\title{
CRIANÇA, INFÂNCIA(S), CRIANÇAS: QUE OBJETIVO DAR A UMA CIÊNCIA SOCIAL DA INFÂNCIA?*
}

Claude Javeau ${ }^{* *}$

\begin{abstract}
RESUMO: A infância designa um conceito polissêmico que reenvia a uma multiplicidade de dimensões ou campos. Se esse conceito é reduzido ao termo "criança", entra-se no campo psicológico; ao termo "infância”, no campo demográfico, o qual se revela ser também de ordem econômica; se se fala de "crianças", entra-se no campo propriamente antropológico ou socioantropológico. A área que essa última dimensão define constitui o verdadeiro objeto susceptível de ser abordado pelas ciências sociais no que diz respeito a essa faixa da população. As pesquisas referentes a esse assunto exigem métodos apropriados. Se no que diz respeito ao momento intersubjetivo relativo à sociedade, correspondendo este ao nível de análise microssociológica, tais métodos podem exigir do pesquisador que ele "se torne criança" a fim de poder reconstituir pela imaginação o universo das culturas infantis. No que diz respeito ao momento institucional, social, propriamente dito, correspondendo ao nível de análise macrossociológico, trata-se de levar em consideração os fenômenos estruturais, particularmente os que concernem à dominação, que afetam as crianças tanto quanto as outras faixas da população, e que se inscrevem numa perspectiva histórica. Esse processo geral de estruturação se aplica também ao universo infantil, e é ele que constitui a chave heurística de toda pesquisa sobre esse universo.
\end{abstract}

Palavras-chave: Dominação. Crianças. História. Método. Estruturação.

* Tradução de Maria Fonseca, com revisão técnica de Ivany Pino.

Este artigo constitui a versão bastante remodelada e aumentada da comunicação que apresentei no colóquio "Sociedades e culturas infantis", organizado na Universidade Charles-de-GaulleLille 3, em novembro de 1997, e publicada nos atos desse colóquio, com o mesmo título: Lille, Coleção UL3 trabalhos e pesquisas, 2000, p. 25-29.

** Professor do Instituto de Sociologia da Universidade Livre de Bruxelas (UlB). E-mail: cjaveau@ulb.ac.be

Educ. Soc., Campinas, vol. 26, n. 91, p. 379-389, Maio/Ago. 2005

Disponível em <http://www.cedes.unicamp.br> 
Criança, infância(s), crianças: que objetivo dar a uma ciência social da infância?

\author{
CHILD, CHILDHOOd(s), CHILDREN: \\ WHICH OBJECTIVE TO GIVE TO THE CHILDHOOD SOCIAL SCIENCE?
}

ABSTRACT: The childhood designates a polysemic concept that remits a multiplicity of dimensions or fields. If this concept is reduced to the term "child", it enters in the psychological field; the term "childhood" in the demographic field, which also reveals to be of economic order; if it talks about "child" it enters in the properly anthropologic or socio-anthropological field. The area that this last dimension defines constitutes the real susceptible object of being broached to the social sciences, regarding this level of population. The researches referring to this subject demand proper methods. With regards to the inter subjective moment related to the society, this corresponds to the level of micro-sociological analysis; such methods may demand from the researcher that he "becomes a child" in order to be able to reconstitute through imagination the universe of children cultures, regarding the institutional, social moment, corresponding to the level of macro-sociological analysis. It has to be taken into consideration the structural phenomena particularly those which concern the domination that affects the children as well as other age population, that subscribe to a historical perspective. This process of general structure is also applied to the child universe; it is the one which constitutes the heuristic key of all research about this universe.

Key words: Domination. Children. History. Method. Structure.

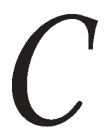

ontrariamente ao que preconizava Durkheim na obra Regras do método sociológico, é legítimo nas ciências sociais duvidar das definições prévias. Parece-me mais vantajoso definir, ainda que sumariamente, campos semânticos capazes de alimentar e aceitar a emergência de objetos de pesquisa específicos, dentro dos quais modelos heurísticos podem ser elaborados servindo para orientar de modo progressivo as pesquisas primeiramente esboçadas em grandes linhas e de modo rudimentar. Com efeito, segundo o conceito epistemológico que defendo, o objeto de pesquisa não é construído ab initio, mas resulta, pelo contrário, ao termo (provisório) de um percurso heurístico, de uma oscilação contínua entre os apuramentos conceituais e as provas empíricas, qualquer que seja a natureza delas.

De um modo geral e necessariamente tosco, a "área de pesquisa" em questão diz respeito aos indivíduos recém-nascidos ou vistos pouco depois do nascimento, nessa faixa de vida que o senso comum chama a 
"infância". Se parece fácil determinar o limite inferior dessa faixa de idade (mas o que dizer do feto: sabe-se, por exemplo, que em numerosas legislaçôes ele é um sujeito de direitos), mais difícil é determinar o superior, na medida em que este varia conforme o país, a época e as diversas divisões do corpo social.

$\mathrm{Na}$ maioria dos países, o direito comum fixa com precisão as idades em que as diversas "maturidades" são proclamadas (e por conseguinte supostas) adquiridas: sexual, civil, política etc. Conforme o contexto institucional, essas idades podem variar consideravelmente. Mas sabe-se, tomando-se em consideração somente os países atualmente mais desenvolvidos, que, se a idade de entrada no mercado de trabalho - e por conseguinte a vida simplesmente - era de apenas 14 anos há alguns decênios para a maioria dos meninos e das meninas, hoje em dia essa idade é muito mais alta. Ao mesmo tempo, o começo da adolescência - fase de experiência que os jovens acima evocados não conheciam pois passavam sem transição da escola primária ao trabalho operário ou agrícola - deslocou-se, quanto a ele, para baixo, de modo que se o coloca por volta dos 10 anos para os adeptos da sociedade de consumo, isto é, para a maioria das faixas demográficas às quais se refere. O período da adolescência se estira, pois, da pré-puberdade até o momento da entrada no mercado de trabalho, isto é, por volta dos 25 anos. E ainda assim certos autores fazem durar a "post-adolescência" até mais ou menos 30 anos. Neste ponto da questão, escolheremos fixar por volta dos 10 anos o limite superior da faixa de idade que nos ocupa, insistindo porém no fato de que se trata somente de uma aproximação cômoda que não se aplica a todas as situações empiricamete detectáveis.

Mas as delimitações demográficas não são as únicas a serem levadas em consideração. Outros pontos de vista o devem ser igualmente. Meu propósito será, pois, o de propor o desbravamento de campos semânticos que, embora concorrentes, podem ser objeto de distinções pertinentes. É claro que o que está enunciado acima são apenas propostas e que, em se tratando de uma tentativa de organização racional de um domínio no qual se manifestam facilmente determinaçōes, até mesmo determinaçōes concorrentes de tipo emotivo, ${ }^{1}$ essas propostas não pretendem de modo algum escapar ao jogo das controvérsias que se situa no âmago mesmo de qualquer processo com pretensão científica. 


\section{A criança}

O campo semântico que tem por denominação o termo "criança" é o primeiro a ser proposto. A conotação desse campo é de ordem psicológica. Com efeito nas disciplinas originadas da psicologia comportamental, o discurso que trata das "fases de desenvolvimento" da criança, considerado de modo canônico, adquiriu uma forte legitimidade. Depois de Piaget, que se deve evidentemente evitar de caricaturar como o faz uma certa doxa para uso de revistas especializadas, assim como de certas escolas onde são formadas as puericultoras, construiu-se um objeto abstrato, a "criança", destinado a passar por níveis diversos e sucessivos na aquisição de competências, cada um deles constituindo uma etapa na fabricação da personalidade dos indivíduos. Em certos textos, essas etapas adquirem uma coloração normativa, pouco se importando com a variedade dos contextos efetivos nos quais indivíduos concretos são chamados a se "desenvolver".

O rebento da burguesia de classe média helvética, por exemplo, não está destinado a ter a educação atropelada que pôde ter uma criança ruandesa na época dos massacres entre etnias.

Seria fútil negar que o trabalho de socialização, ele mesmo dividido em uma fase "primária" e em várias fases "secundárias", não se insere num substrato biológico cuja universalidade não pode ser contestada. Mas nem mesmo esse substrato escapa à "construção social da realidade". ${ }^{2}$ Como para com os "velhos", a infância é objeto de uma definição social, mais ou menos partilhada pela população interessada. De um certo modo, e por paradoxal que essa afirmação possa parecer, não se nasce criança, vem-se a sê-lo. Há ainda neste planeta muitos lugares onde a maneira de se tornar criança não tem nada a ver com uma sinecura, nem com uma história de nursery, de creche ou de kindergarten.

Uma variante desse paradigma, no sentido lingüístico do termo, encontra-se na imagem do aluno visto sob o ângulo de competências cognitivas e comportamentais, entre outras, tais como são tomadas a cargo pela instituição escolar. Nesse caso também, o modo de aquisição dessas competências passa muitas vezes por caracterizações normativas. Essa normatividade se inscreve no mais profundo da pedagogia escolar, nas suas diversas variantes. Não é minha intenção contestar a existência dessa normatividade, mas sim mostrar sua camuflagem sob o álibi da objetividade científica. A escola é um dos lugares essen- 
ciais onde se forjam as modalidades de integração dos mais jovens à sociedade global, ao lado da família (cujo papel neste sentido teria tendência a enfraquecer), dos grupos de pares (muitas vezes constituídos na escola, mas podendo também surgir da "rua" em geral), dos diversos dispositivos próprios à cultura do divertimento de massa.

A sociologia chamada da educação endossou essa imagem particular da criança, considerada ora um "indivíduo" no sentido estatístico da palavra (macrossociologia do "rendimento escolar", em particular), ora um "ator" num sistema de significações chamado estabelecimento escolar, até mesmo em escala menor, a de classe (etnometodologia das relações pedagógicas) (Van Haecht, 1998). A dimensão psicológica, sem ser abandonada, passa ao segundo plano servindo somente para a explicação eventual dos desvios relativos aos modelos normativos adotados às vezes sem distanciamento crítico (aluno retardado, violento, mau-caráter etc.). Essa consideração nos leva ao nosso segundo campo semântico.

\section{A infância}

A infância constitui o nosso segundo campo semântico. Esse paradigma se inscreve no ponto de partida numa perspectiva demográfica. Esbocei-a acima. Às faixas de idade constituindo a "infância propriamenta dita" sucedem com efeito as da adolescência, da idade adulta, da terceira, da quarta idade etc. O seu elo com um discurso macroeconômico, eventualmente recoberto por um discurso de tipo macrossociológico se inscrevendo na corrente dominante (main trend sociology), tornou fácil abordar a questão sob o ângulo dos custos, aqui privilegiado. A infância, com efeito, demograficamente falando, é geralmente considerada improdutiva, pelo menos nas nossas latitudes, onde a obrigação escolar é largamente respeitada, ultrapassando amplamente, no sentido inferior, o limite fixado pela lei, graças à generalização, pelo menos em certos países, das creches e dos jardins-de-infância.

No rasto desse paradigma econômico, a imagem do aluno é vista como uma ocasião de investimento. A escola é assimilada a um sistema de produção de competências, cujo efeito diferido é suposto ser útil à conservação e se possível ao incremento do bem-estar material, componente essencial do sistema social global. A demografia escolar, aplicada às gerações sucessivas de alunos, estuda em particular os fluxos de entrada e os fluxos de saída nas escolas, sob o ângulo do critério do êxito 
(sendo este um substrato de uma avaliação do "rendimento" do sistema escolar). A essas análises quantitativas corresponde um imperativo aparentemente ético (chamado às vezes "direito ao êxito"), que disfarça na realidade um imperativo econômico, melhor dito contabilista, importante, o de limitar as despesas escolares. De resto, o aluno cuja imagem ultrapassa o quadro demográfico da infância, para se instalar no âmago do quadro da adolescência, torna-se uma componente, a mesma do jovem delinqüente, entre outras, de uma infância que se elabora conceitualmente de maneira diversa, sob a forma das infâncias.

Aluno, jovem delinqüente, "pequeno trabalhador infatigável", cada uma dessas imagens da infância reenvia a uma trajetória ideal-típica, e é devedora de uma macrossociologia específica, que busca na criminologia a idéia de "passagem ao ato". Essa opção metodológica contribui para ocultar o que há de particular no gênero de vida, na qualidade de sistema de ação construído pelos atores, desse gênero próprio à infância, e que o recurso a um paradigma de natureza antropológica, as crianças, permite abordar de modo menos redutor, ou, para retomar a expressão de Georges Balandier, menos "ortopédico". A passagem do demográfico ao econômico, ademais, tem a ver com todas as categorias de idade. As sociedades desenvolvidas fazem face ao problema, cuja amplidão só tende a aumentar: trata-se da diminuição relativa da participação da faixa de idade realmente ativa na sociedade global. Cabe aos jovens assumirem uma parte importante das conseqüências provocadas pelo envelhecimento de uma população cuja esperança de vida tem aumentado sensivelmente. E, ao mesmo tempo, despesas ocasionadas pela conservação de um sistema escolar freqüentado cada vez mais tempo e cada vez mais exigente em termos de capitais humanos e materiais. Atualmente esses problemas se colocam como pano de fundo de uma mudança institucional considerável, induzida pela passagem de um modelo keynesiano-fordista a um modelo neoliberal, melhor dito, neopaleoliberal.

\section{As crianças}

Trata-se aqui do meu terceiro campo semântico, de coloração deliberadamente antropológica. Os indivíduos reagrupados sob esse nome constituem um "território", no sentido literal (as populações ditas "primitivas") ou metafórico do termo, de contorno mais ou menos preciso no tempo e no espaço, com suas estruturas e seus modelos de comporta- 
mentos particulares, seus "gêneros de vida, isto é, seus sistemas de ação construídos pelos próprios atores" (Juan, 1991). Segundo esse paradigma as crianças devem ser consideradas uma população ou um conjunto de populações com pleno direito (científico), com seus traços culturais, seus ritos, suas linguagens, suas "imagens-açôes" ou, menos preciso no tempo e no espaço, com suas estruturas e seus "modelos de açôes" etc. Evidentemente está ligada a esse paradigma a noção de sucedâneo "infantil” de cultura a vir, mas como um meio e um modo de construção da realidade social irredutível a outros (e particularmente ao das pessoas idosas de quem se diz que "voltaram a ser criança"). As crianças não devem desde então ser vistas como um universo prefigurando o dos adultos, e ainda menos como uma cópia imperfeita do mundo adulto. É essa uma tentação freqüente entre os especialistas do "merchandising", à qual uma antropologia digna desse nome deve dar as costas.

A sociologia clássica, sobretudo quando ela privilegia técnicas quantitativas, está mal instrumentada para abordar os territórios das crianças. Não somente estas são pouco aptas (e dispostas) a responder a questionários estandardizados, mas os aspectos estudados, fora a freqüência com a qual aparecem (popularidade de um brinquedo, por exemplo, ou difusão de um traço lingüístico), acham-se dificilmente nos cálculos estatísticos. É que se trata antes de tudo de pôr em evidência as significações que as crianças atribuem aos diversos componentes dos estilos de vida que levam, tanto na perspectiva da constituição bruta de uma cultura específica quanto na da relação desta com os diversos processos de socialização em ação, dos quais um grande número surge na realidade da auto-socialização, qualquer que seja o quadro: família, escola, rua, terreno vago, colônia de férias etc.

As regras da metodologia antropológica aparecem desde então mais pertinentes. Elas não excluem que se tome em consideração os subconjuntos constituídos por elos de classe, de referências étnicas, de "patrões" de atividades particulares, como se pode ver nas escolas, de jovens delinqüentes, de jovens doentes, de jovens submetidos ao trabalho forçado, de jovens burgueses que "se entediam aos domingos", meninos entre si, meninas entre elas etc. Representar as crianças como se fossem bambaras ou bororos não quer dizer que se despreze os modos de estruturação próprios dos tempos modernos, até mesmo pós-modernos. Desse ponto de vista, a antropologia contemporânea desenvolveu procedimentos que levam em conta complexidades inscritas no âmago das sociedades chama- 
das "desenvolvidas". De modo nenhum é necessário evocar, para justificar o projeto antropológico, a preeminência nas crianças de um "pensamento primitivo". Esta hipótese, em razão das condições nas quais se desenvolve a primeira educação sob nossas latitudes, parece pouco admissível. Não conviria confundir, com efeito, pensamento "primitivo" e pensamento "mágico". Os especialistas do desenvolvimento dos primeiros anos de vida recorrem muitas vezes a esta noção, que reenviaria um pouco ao primeiro estado comtiano. Não é certo que se possa confiar-lhe a tarefa de preencher totalmente a relação ao mundo das crianças como segmento de população mais ou menos cuidadosamente delimitável. Existiria perfeitamente uma racionalidade infantil que deitaria por terra toda tentativa de fazer das crianças uma espécie de "primitivos" numa escala de evolução cultural, que faria eco a um darwinismo social ao qual a antropologia clássica nem sempre soube renunciar.

O ângulo de mira da "vida cotidiana" (Juan, 1991) convém particularmente ao nosso próposito, na medida em que ele leva em conta ao mesmo tempo comportamentos, representações e contextos de naturezas múltiplas. A vida cotidiana das crianças comporta, como qualquer outra, sua parte de alienação a rotinas mais ou menos constrangedoras, de cotidianidade, no sentido em que Lefebvre dava a este termo. Para as crianças, não se trata apenas de assimilar as disciplinas que lhes devem permitir se integrarem nos diversos grupos dos quais elas fazem parte, mas também de consolidar o sentimento de segurança ontológica (Giddens), sem o qual a existência no dia-a-dia só pode ser uma aventura terrífica. Infelizmente é verdade que, atualmente, o terror é a sina de muitas crianças. Mas, se a sociedade das crianças comporta projetos, ela é também balizada por ritos, frutos, muitas vezes, de transações espontâneas com o mundo dos adultos. Projetos e ritos constituem, entre outros, excelentes objetos de investigaçôes. Sem dúvida, para levá-las a bom porto, é necessário afinar instrumentos metodológicos aplicáveis a populações tão singulares. Como para qualquer outro objeto, o pesquisador deve praticar o "olhar distanciado" celebrado por Claude Levi-Strauss. Mas, assim fazendo, ele deve também, nesta circunstância, reencontrar uma "alma de criança”. Nessa perspectiva, a aplicação da exigência de empatia não é, sem dúvida, a tarefa mais fácil de se executar.

Como os outros grupos sociais, as crianças arranjam ${ }^{3}$ suas existências cotidianas com os meios que podem. Esses meios lhes são dados pelos dispositivos de socialização que lhes são impostos ou propostos. Nos 
países ricos, os meios de comunicação de massa, compreendendo também atualmente os processos informáticos (o Net), ocupam no centro desses dispositivos um lugar privilegiado. Entre as competências esperadas das crianças, de agora em diante, até mesmo exigidas, o domínio da manipulação informática tornou-se imperativo. Não se poderia esquecer de levar em consideração, no que diz respeito às crianças de diversos meios (e não só às das sociedades desenvolvidas), as importantes modificações advindas em torno delas, entre as quais a mais imediata que lhes possa passar pela cabeça é a família. Segundo as diversas recomposições podendo se reproduzir no seio desta, os papéis dos "outros significativos" são desempenhados por uma multiplicidade de pessoas que se tornam outros tantos personagens: padrastos, madrastas, concubinos, concubinas etc., que podem ser, num casal, do mesmo sexo. Isso supõe que reencontrar "uma alma de criança", não obstante um arranjo melhor, do que o que se tinha outrora, das vias de passagem entre os universos adultos e os universos infantis, constitui certamente, atualmente, um desafio cada vez mais difícil de levantar.

O grupo (ou a configuração) é seguramente o objeto mais indicado para uma investigação do tipo socioantropológico. É dentro dele que se elaboram as culturas infantis (falar de uma só "cultura infantil", salvo em termos de "forma", no sentido simmeliano do termo, seria, com efeito, extremamente redutor), em função de determinantes de ordem macrossocial que intervêm no processo de estruturação do qual esse grupo participa, como todos os outros. Pois não se pode esquecer que é com relação à sociedade global que as práticas e representações desse grupo tomam suas significações e formam seus esquemas de atividades. Se as crianças produzem, sem exprimi-lo, um conjunto de feitos culturais que constituem construções sociais "em constante redefinição (intervindo) na regulação das relaçôes sociais e no conjunto das tranformaçôes da sociedade" (Mollo-Bouvier, 2000, p. 39-44), é bem porque as estruturas nas quais se inscrevem essas relaçôes concernem às crianças da mesma maneira que às outras fraçôes da sociedade. Sem dúvida dizê-lo é um truísmo, mas talvez não seja fora de propósito lembrar que, em oposição a uma visão por demasiado microssociológica das coisas, o grupo social das crianças participa dos fenômenos de dominação que concernem à sociedade inteira. Junto com o desdobramento dos efeitos do desenvolvimento biológico, dos efeitos do desenvolvimento simbólico (o que chamamos ordem cultural das coisas), dos efeitos do desenvolvimento das relações de 
poder, desde o microcosmo familiar até as bases propriamente políticas da sociedade, não se deve nunca perder de vista a dimensão social das combinações intersubjetivas, devedora de uma análise microssociológica, constituindo somente um dos momentos da estruturação, sendo o outro, segundo a concepção dualista legitimamente posta em evidência por Giddens, a dos sistemas institucionais, do social objetivado, devedor de uma análise macrossociológica. Contentar-se com somente um desses momentos seria dar provas de um defeito de miopia heurística, criticável, quer se trate das crianças ou de qualquer outro "território" da sociedade global. Aqui o processo metodológico requer, pois, uma entrada duplicada: em primeiro lugar, a das interaçóes se travando e estabelecendo continuamente dentro do território das crianças e entre esse território e os outros territórios aos quais aquele está ligado; em segundo, as interaçôes das instituições que, dentro de uma sociedade dada, enquadram a existência cotidiana dos habitantes do território mencionado. Essa entrada, não o esqueçamos, não pode fazer a economia do recurso a uma perspectiva histórica. Todo dispositivo institucional possui sua densidade diacrônica. $\mathrm{O}$ antropólogo das crianças não somente deve esforçar-se para reencontrar uma "alma de criança" mas deve também adquirir uma alma de historiador, dobrada, se for o caso, de uma alma de jurista e de uma de economista. Como se vê, praticar a "sociologia da infância", como qualquer outra aliás, exige das equipes de especialistas que se dedicam a esse campo, ainda em plena elaboração, um leque de competências extremamente variadas. Ainda que de maneira lapidar, espero ter mostrado a pertinência dessa exigência.

Recebido em novembro de 2004 e aprovado em março de 2005.

\section{Notas}

1. Viu-se na Bélgica, quando foram descobertos os crimes cometidos por Dutroux e gente da mesma laia: no auge da emoção coletiva, os jornais chamaram sistematicamente de "meninas" duas jovens flamandas, An e Eefje, igualmente vítimas dos mesmos criminosos. Ora, uma delas, juridicamente maior de idade no momento da sua morte, tinha a mesma idade que Diana, Princesa de Gales, quando essa se casou.

2. Esse é o título de uma obra célebre de P. L. Berger e Th. Luckmann, publicada pela primeira vez em inglês em 1962.

3. O autor utiliza aqui o verbo "bricoler" e em nota ao pé da página remete a: Javeau, Le bricolage du social, Paris: PUF, coll. Sociologie d'Aujourd'Hui, 2001. 


\section{Referências bibliográficas}

BERGER, P.; LUCKMANN, T. La construction sociale de la réalité. Paris: Méridiens-Klincksieck, 1986.

JUAN, S. Sociologie des genres de vie. Paris: PUF, 1991. Coll. Le Sociologue. JAVEAU, C. Enfant, enfance, enfants: quel object pour une science sociale du jeune âge? In: SAAdi-Mokrane, D. (Éd.). Sociétés et cultures enfantines. Paris: Université Lille 3, 2000. p. 25-29. Coll. ul 3 travaux et recherches.

JAVEAU, C. Sociologie de la vie quotidienne. Paris: PUF, 2003. Coll. Que sais-je?

JAVEAU, C. Le bricolage du social. Paris: PUF, 2001. Coll. Sociologie d'aujourd'hui.

MOLLO-BOUVIER, S. Les dimensions sociologiques des modes de vies des enfants. In: Actes de Colloque "Sociétés et cultures enfantines", Université Charles-de-Gaulle-Lille 3, novembre 1997. Lille, Collection UL3 travaux et recherches, 2000, p. 39-44.

VAN HAECHT, A. L'école à l'épreuve de la sociologie. 2. éd. Bruxelles: De Boeck Université, 1998. 